\title{
Two roads for oncolytic immunotherapy development
}

\author{
Howard L. Kaufman ${ }^{1,2^{*}}$ (D) and Praveen K. Bommareddy ${ }^{3}$
}

\begin{abstract}
Oncolytic viruses are an emerging class of immunotherapy agents for cancer treatment. In this issue of JITC, Machiels et al. reports early phase data from an oncolytic adenovirus given by intravenous (IV) administration. While this may allow easy access to metastatic lesions, there is limited data supporting the therapeutic effectiveness of this approach. Further studies should include assessment of viral replication in tumor tissue and consider comparative trials using IV and intratumoral delivery to fully optimize oncolytic immunotherapy.
\end{abstract}

Oncolytic immunotherapy (OI) is a new approach for cancer treatment that utilizes live or heat-inactivated viruses that preferentially replicate in tumor cells, induce immunogenic cell death (ICD), and initiate host anti-tumor immunity [1]. Globally, there are three approved oncolytic viruses, an adenovirus (H101) for the treatment of advanced head and neck cancer in China, Rigvir, an oncolytic reovirus approved for the treatment of advanced melanoma in Estonia, Latvia, Poland and Belarus, and most notably, talimogene laherparepvec (T-VEC), an oncolytic herpes simplex virus, type 1 (HSV-1) approved for the treatment of advanced melanoma in the United States, Europe and Australia [1,2]. The ability of oncolytic viruses $(\mathrm{OVs})$ to induce ICD and recruit lymphocytes into the tumor microenvironment has generated considerable interest in using OVs as part of combination regimens designed to enhance the therapeutic effectiveness of cancer immunotherapy. Indeed, recent clinical reports have supported a significant therapeutic benefit when T-VEC was used in combination with immune checkpoint inhibitors in melanoma [3, 4]. As a class, OVs can be differentiated from other forms of immunotherapy in being live, replicating agents that can be amplified in vivo (at least until neutralized by the host immune system), having a tolerable safety profile (largely causing low grade constitutional symptoms and local injection site reactions), and to date, most have been delivered by intra-tumoral

\footnotetext{
* Correspondence: HLKaufman@mgh.harvard.edu

'Division of Surgical Oncology, Massachusetts General Hospital, 55 Fruit Street, Warren 401, Boston, MA 02114, USA

${ }^{2}$ Replimune, Inc., Woburn, MA, USA

Full list of author information is available at the end of the article
}

(IT) injection [5]. While IT administration allows maximal delivery of high viral titers to tumors, bypasses systemic neutralization and prevents premature clearance, IT delivery can cause logistical and biosafety concerns especially when used in busy ambulatory or in-patient clinical settings. Further, many patients harbor metastatic disease at sites not easily palpable, and require localization via interventional imaging or surgical exposure, which may be challenging for OVs that require repeated administrations over time. The potential to delivery OVs by IV administration theoretically allows for viral distribution to tumors at any site and precludes the need for additional training and interventional procedures associated with IT delivery.

In this issue of JITC, Machiels et al. report the results of a Phase I clinical trial using an intravenously (IV) delivered chimeric adenovirus, enadenotucirev, in patients with advanced epithelial solid tumors [6]. This virus was developed specifically on the basis of its blood stability and potential suitability for IV administration. In the study, 61 patients were treated initially in a standard dose escalation design with viral doses of $1 \times 10^{10}-1 \times 10^{13}$ viral particles (vp) given on days 1, 3 and 5, and subsequent patients treated in an expansion cohort or using various schedules of virus delivery. Enadenotucirev treatment was associated with typical OV adverse events with the most common treatment-emergent grade 3 or greater adverse events being hypoxia, lymphopenia and neutropenia. The trial established a dose of $3 \times 10^{12} \mathrm{vp}$ as the maximum tolerated dose, and an additional 9 patients were treated in an expansion cohort at this dose with further patients enrolled to evaluate weekly and every three-week dosing schedules. Although no objective responses were seen, the 
authors concluded that the study supports further clinical investigation of IV enadenotucirev in combination with other agents. Although the study provides important safety and dosing information, does it truly support the potential therapeutic effectiveness of IV administration for OVs and what other data would be helpful to better evaluate the impact of IV administration in lieu of objective tumor regression?

In a prior trial of enadenotucirev, 17 patients with a variety of primary solid tumors received a single IV dose of virus and 8-15 days later underwent tumor resection [7]. In this study, tumor specimens had evidence of virus by IHC and confirmed by PCR assay. In the Machiels et al. study, evidence for active OV accumulation at the tumor site was evaluated in one patient with metastatic colorectal cancer who had an abdominal wall metastasis available for biopsy 39 days after treatment. In this patient, who had received enadenotucirev in every three-week schedule, biopsy revealed extensive necrosis and viral infection of tumor cells was seen by immunohistochemistry and viral replication confirmed by qPCR of viral DNA sequences, consistent with the data from the earlier trial. While PCR is a highly sensitive assay for viral sequences, confirmation of live viral particles and on-going replication cannot be established. Additional studies of local viral protein expression or recovery and plaque assay of live viruses with determination of viral titers pre- and post-treatment might be more informative. The issues with IV delivery of any OV includes considerable dilution in the systemic circulation and the likelihood of premature neutralization through serum anti-viral immunoglobulins or other serum proteins, especially after multiple infusions. Thus, confirmation that effective virus is delivered to metastatic lesions is necessary when evaluating IV delivery and may differ depending on the viral species, host immune response and history of prior viral exposure and features of the local tumor microenvironment that may impede effective viral delivery to sites of tumor growth.

To date, there have been only a few published reports of IV delivery of OVs and the key findings from these studies are summarized in Table 1 . In addition to the current report by Machiels et al. in this issue of JITC, as mentioned above, enadenotucirev was previously evaluated in a phase 1 mechanism of action study in 17 patients with solid tumors scheduled for primary resection were treated with intravenous virus $\left(1 \times 10^{12}\right.$ vp on days 1,3 and 5) followed by operation on days 8-25 [7]. This study is the only one to include a comparator cohort of patients with colorectal cancer treated by IT injection, although this was limited to only five subjects. The investigators assessed the presence of virus within tumor by immunohistochemical (IHC) staining for nuclear viral hexon protein expression and $\mathrm{qPCR}$ for viral DNA sequences. Virus was detected in tumor tissue by both injection methods, but while virus was more commonly confirmed in IV-treated tumors, intense hexon IHC staining $(>8-\%)$ was more common in IT-treated lesions. The authors, however, did not report viral titers from the tumor sites.

Several other OVs have been tested in early phase clinical trials with similar results (Table 1). ONYX-015 was a replication competent E1B-deleted adenovirus that selectively replicates in tumor cells harboring p53 mutations. A small ten patient study of ONYX-015 in patients with advanced solid tumors metastatic to the lung was conducted with IV delivery weekly in 21 day cycles [8]. Virus was detected in plasma by PCR analysis and one patient had intratumoral virus detected by IHC and PCR. ONYX-015 was also delivered by IV delivery every two weeks in a phase 2 study of 18 patients with treatment refractory colorectal cancer [9]. In this study, $36 \%$ of patients had viral DNA detected by PCR in plasma $72 \mathrm{~h}$ after the last treatment and one patient who died of disease progression was found to have virus by IHC and PCR in the spleen and normal liver at autopsy with very low levels in tumor tissue. A phase I study of an oncolytic Seneca Valley virus was conducted in 30 patients, six with small cell lung cancer and 24 with carcinoid tumors [10]. The virus was given by a single IV delivery using a dose escalation design and viral titers in blood were seen at day 3 by PCR. In one patient who died tumor tissue was obtained and virus was detected by IHC. Pexa-Vec is a thymidine kinase gene-deficient oncolytic vaccinia virus encoding GM-CSF and was evaluated in 15 patients with treatment-refractory colorectal cancer with increasing doses given by IV delivery every two weeks [11]. Infectious viral titers were detected in plasma two hours after cycle 1 and $30 \mathrm{~min}$ after cycle 4 , as well as low doses in throat swabs 5-8 days after treatment, but no tumor was assessed for presence of virus. Using a Western Reserve strain of vaccinia virus, a phase 1 study in 11 patients with advanced colorectal cancer were treated with a single IV dose in a dose escalation design [12]. Virus was detected in blood on days 3 and 8 while two patients had virus found in tumor tissue by PCR analysis. ICOVIR-5 is a modified oncolytic adenovirus that has a deletion of the E1A region and has an RGD sequence inserted at the HI loop of the fiber knob to target integrins and assist in tumor cell entry [13]. Twelve advanced cutaneous and uveal melanoma patients were treated with a single dose of ICOVIR-5 at increasing doses. The authors reported that 2 of 3 patients at the higher doses had virus detected by qPCR assay. Across all these studies adverse events were largely low grade constitutional symptoms and no objective clinical responses were seen. 


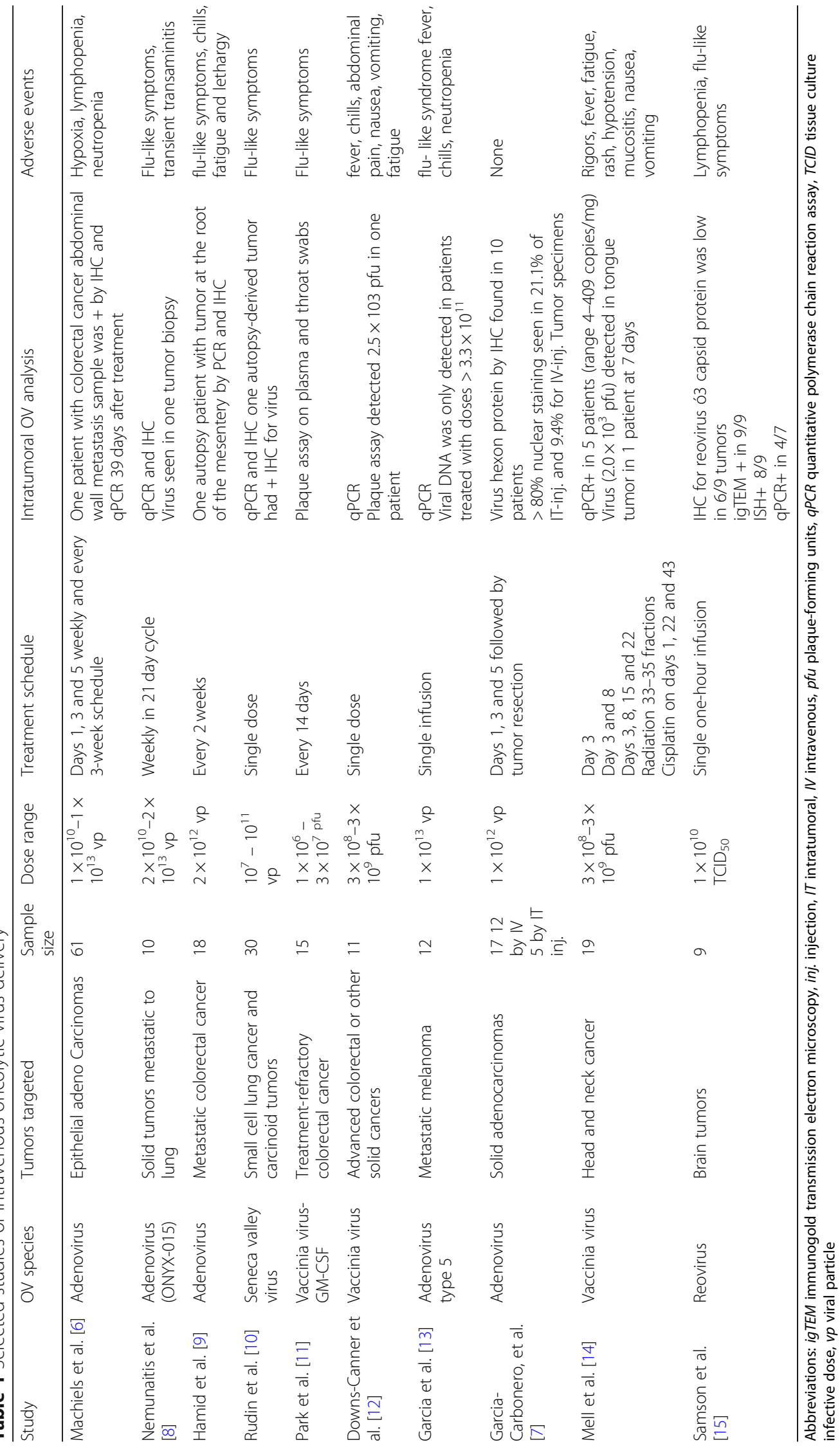

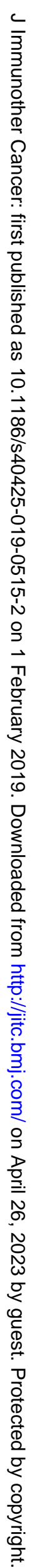


GL-ONC1 is a modified oncolytic vaccinia virus, which has been administered intravenously in combination with chemoradiation therapy in patients with primary locoregional head and neck carcinomas [14]. In a phase 1 dose finding trial, 19 patients were treated and the OV was well tolerated with the most common adverse events being grade 1-2 rigors, fever, fatigue, and rash. More serious grade 3 adverse reactions included hypotension, mucositis, nausea, and vomiting. The investigators detected $\mathrm{OV}$ by $\mathrm{qPCR}$ assay in 4 patient resected tumors and 1 patient demonstrated live virus in a tongue neoplasm 7 days after receiving the first dose of virus. In another trial using an oncolytic orthoreovirus, patients with high-grade glioma and CNS metastases from solid tumors were treated with a single IV administration followed by resection [15]. The authors reported a tolerable safety profile with an increase in $\mathrm{T}$ cell infiltration and local interferon and PD-1/PD-L1 expression following OV delivery. In this study they examined viral presence through multiple assays on post-resection tumor specimens and reported that reovirus ó3-capsid protein expression was detected at low levels in 6 of 9 tumor specimens. Using in situ hybridization of reovirus RNA was detected in 8 tumors and using an immunogold transmission electron microscopy technique, virus was detected in all 9 specimens. In addition, the investigators utilized a qPCR assay but found viral copies in only 4 of the 9 tumor biopsies highlighting the limitations of PCR analyses.

Collectively, the clinical data thus far suggest that while IV delivery of OVs across several different viral species is safe and well tolerated, detection of high titers at tumor sites has not been clearly demonstrated by IV delivery. Viral biodistribution represents a significant challenge as many OVs will be able to infect both normal and neoplastic cells. Although most OVs undergo abortive replication in normal cells, these cells which may include easily accessible immune cells, can harbor viral particles and prevent effective delivery to the tumor site. In addition, rapid clearance of virus through both pre-existing and induced antibody titers, as well as through binding of some viruses to serum proteins, may further limit delivery of virus to tumor sites. This issue may become more pronounced over time in patients treated with multiple viral infusions. Thus, how can we move forward? Further clinical investigation should include sensitive and accurate assessment of viral titers recovered from tumor sites in patients treated with OVs in early phase clinical trials. As shown by the limited data in Table 1, quantitative PCR assay may not be reliable in confirming live virus. An attempt to evaluate neutralizing anti-viral antibody titers is also important to better understand how this mechanism may limit viral delivery to tumors. Further consideration of clinical studies that compare IV and IT delivery would also be important for understanding the nuances and potential of each approach. The final arbiter of success will likely be evidence of tumor regression and, while the current studies focused on IV administration are early and not designed to evaluate therapeutic activity, to date no evidence for clinical responses have been observed. Prior to embarking on large combination clinical trials, it may be prudent to understand the biology of OV delivery in more detail to better optimize dosing, schedules and routes of administration.

As Robert Frost wrote,

"Two roads diverged in a wood, and I-.

I took the one less traveled by,

And that has made all the difference."

\section{Acknowledgements}

The authors wish to thank Dr. Sam Rabkin for useful discussions.

Funding

Not applicable

Availability of data and materials

Not applicable

\section{Authors' contributions}

HLK conceived the concepts and drafted the initial version of the manuscript. PKB provided additional comments and writing assistance and helped format references and develop the table. Both authors read and approved the final manuscript.

\section{Ethics approval and consent to participate}

Not applicable

\section{Consent for publication}

Not applicable

\section{Competing interests}

H.L. Kaufman is an employee of Replimune, Inc.

\section{Publisher's Note}

Springer Nature remains neutral with regard to jurisdictional claims in published maps and institutional affiliations.

\section{Author details}

${ }^{1}$ Division of Surgical Oncology, Massachusetts General Hospital, 55 Fruit Street, Warren 401, Boston, MA 02114, USA. ${ }^{2}$ Replimune, Inc., Woburn, MA, USA. ${ }^{3}$ Rutgers Graduate School of Biomedical Sciences, New Brunswick, NJ, USA.

Received: 13 November 2018 Accepted: 20 January 2019

Published online: 01 February 2019

\footnotetext{
References

1. Bommareddy PK, Shettigar M, Kaufman HL. Integrating oncolytic viruses in combination cancer immunotherapy. Nat Rev Immunol. 2018;18:498-513.

2. Andtbacka RH, et al. Talimogene Laherparepvec improves durable response rate in patients with advanced melanoma. J Clin Oncol. 2015;33:2780-8.

3. Ribas A, et al. Oncolytic Virotherapy Promotes Intratumoral T Cell Infiltration and Improves Anti-PD-1 Immunotherapy. Cell. 2017;170:1109-1119 e1110.

4. Chesney J, et al. Randomized, open-label phase II study evaluating the efficacy and safety of Talimogene Laherparepvec in combination with Ipilimumab versus Ipilimumab alone in patients with advanced, Unresectable Melanoma. J Clin Oncol. 2018;36:1658-67.

5. Bommareddy PK, Silk AW, Kaufman HL. Intratumoral approaches for the treatment of melanoma. Cancer J. 2017;23:40-7.
} 
6. S. R. Machiels JP, Rottey S, et al. A phase 1 dose escalation study of the oncolytic. adenovirus enadenotucirev, administered intravenously to patients with epithelial solid. Tumors (EVOLVE). J Immunother Cancer. 2018.

7. Garcia-Carbonero R, et al. Phase 1 study of intravenous administration of the chimeric adenovirus enadenotucirev in patients undergoing primary tumor resection. J Immunother Cancer. 2017:5:71.

8. Nemunaitis J, et al. Intravenous infusion of a replication-selective adenovirus (ONYX-015) in cancer patients: safety, feasibility and biological activity. Gene Ther. 2001;:8:746-59.

9. Hamid O, et al. Phase II trial of intravenous $\mathrm{Cl}-1042$ in patients with metastatic colorectal cancer. J Clin Oncol. 2003;21:1498-504.

10. Rudin CM, et al. Phase I clinical study of Seneca Valley virus (SW-001), a replication-competent picornavirus, in advanced solid tumors with neuroendocrine features. Clin Cancer Res. 2011;17:888-95.

11. Park SH, et al. Phase $1 \mathrm{~b}$ trial of biweekly intravenous Pexa-Vec (JX-594), an oncolytic and immunotherapeutic vaccinia virus in colorectal Cancer. Mol Ther. 2015:23:1532-40.

12. Downs-Canner $\mathrm{S}$, et al. Phase 1 study of intravenous oncolytic poxvirus (vvDD) in patients with advanced solid cancers. Mol Ther. 2016;24:1492-501.

13. Garcia M, et al. A phase 1 trial of oncolytic adenovirus ICOVIR-5 administered intravenously to cutaneous and uveal melanoma patients. Hum Gene Ther. 2018. https://doi.org/10.1089/hum.2018.107. [Epub ahead of print].

14. Mell LK, et al. Phase I trial of intravenous oncolytic vaccinia virus (GL-ONC1) with cisplatin and radiotherapy in patients with Locoregionally advanced head and neck carcinoma. Clin Cancer Res. 2017;23:5696-702.

15. Samson A, et al. Intravenous delivery of oncolytic reovirus to brain tumor patients immunologically primes for subsequent checkpoint blockade. Sci Transl Med. 2018;10

Ready to submit your research? Choose BMC and benefit from:

- fast, convenient online submission

- thorough peer review by experienced researchers in your field

- rapid publication on acceptance

- support for research data, including large and complex data types

- gold Open Access which fosters wider collaboration and increased citations

- maximum visibility for your research: over $100 \mathrm{M}$ website views per year

At $\mathrm{BMC}$, research is always in progress.

Learn more biomedcentral.com/submissions 
Correction: Two roads for oncolytic immunotherapy development

Kaufman HL, Bommareddy PK. Two roads for oncolytic immunotherapy development. J Immunother Cancer 2019;7:26. doi: 10.1186/s40425-019-0515-2

This correction notice is to note that second sentence of the first paragraph should be corrected from

'Globally, there are three approved oncolytic viruses, an adenovirus (H101) for the treatment of advanced head and neck cancer in China, Rigvir, an oncolytic reovirus approved for the treatment of advanced melanoma in Estonia, Latvia, Poland and Belarus, and most notably, talimogene laherparepvec (T-VEC), an oncolytic herpes simplex virus, type 1 (HSV-1) approved for the treatment of advanced melanoma in the United States, Europe and Australia. ${ }^{12}$

To

'Globally, there are three approved oncolytic viruses, an adenovirus (H101) for the treatment of advanced head and neck cancer in the People's Republic of China; Rigvir, an oncolytic echovirus approved for the treatment of advanced melanoma in some Eastern European countries; and most notably, talimogene laherparepvec (T-VEC), an oncolytic herpes simplex virus, type 1 (HSV-1) approved for the treatment of advanced melanoma in the United States, Europe, Australia and Israel. ${ }^{1} 2$

Open access This article is distributed under the terms of the Creative Commons Attribution 4.0 International License (http://creativecommons.org/licenses/by/4.0/), which permits unrestricted use, distribution, and reproduction in any medium, provided you give appropriate credit to the original author(s) and the source, provide a link to the Creative Commons license, and indicate if changes were made. The Creative Commons Public Domain Dedication waiver (http://creativecommons.org/ publicdomain/zero/1.0/) applies to the data made available in this article, unless otherwise stated.

C Author(s) (or their employer(s)) 2021. Re-use permitted under CC BY. Published by BMJ.

J Immunother Cancer 2021;9:e0515-2corr1. doi:10.1136/s40425-019-0515-2corr1

Check for updates 